\title{
A Study of Anisotropic Cellulose Acetate Membrane: An Application to Wastewater Treatment
}

\author{
MUKESH KUMAR, AMIT KUMAR SHARMA and MEENA SHARMA* \\ Department of Chemistry, University of Jammu, Jammu 180006, India \\ mlakhanpal89@rediffmail.com
}

Received 22 October 2013 / Accepted 22 November 2013

\begin{abstract}
Anisotropic cellulose acetate membrane was prepared by impregnating cellulose acetate solution through a G2 sintered disc. Various water samples from different water sources as well as from different industries have been collected. Various parameters such as $\mathrm{pH}$, conductivity, viscosity and ion analysis have been carried out between two types of water samples i.e. water samples directly collected from different water sources as well as from different industries and water samples after transport across anisotropic cellulose acetate membrane. Anisotropic cellulose acetate membrane was found to be quite efficient in removing some acidic species indicated by increase in $\mathrm{pH}$ and removal of ionic species indicated by decrease in specific conductance and anion chromatographic studies.
\end{abstract}

Keywords: Cellulose acetate, $\mathrm{pH}$, Conductivity, Viscosity, Ion chromatography

\section{Introduction}

Membrane technology is a multi-disciplinary separation technology. The main force of membrane technology is that it works without the addition of chemicals and with a relatively low energy use. Membranes have gained an important place in chemical technology and are used in broad range of applications. The key property that is exploited is the ability of a membrane to control the permeation rate of a chemical species through the membrane.A membrane is a selective barrier between two phases, the term selective being inherent to a membrane or a membrane process ${ }^{1}$. This statement implies that the membranes can be gaseous, liquid, solids or combination of these phases. A membrane may be defined as an interphase separating two phases and selectively controlling the transport of materials between these phases ${ }^{2}$. Membrane technology has shown high promise in starch processing industry for reducing evaporation costs, improving product recovery and removing solids before wastewater treatment ${ }^{3}$. The use of the membrane technologies has been proposed for applications in the fusion reactor fuel cycle in order both to reduce the number of process units and operate in continuous mode ${ }^{4-6}$. Therefore, several applications have been studied to apply the membrane technologies for process operations in the fuel cycle in alternative to the traditional processes based on molecular sieves or cryogenic traps. The separation features of 
membrane systems, when coupled to chemical biotransformation, permit reduction in plant space, in capital costs and generally, better overall performances. Membranes can be used as chromatographic supports and with various surface chemistries, offer a wide range of possibilities ${ }^{7}$. Membranes have also recently been used as an adsorptive medium because of their very high internal surface area, their ability to treat both suspensions and solutions simultaneously and their inherent speed due to convective rather than diffusive flow. In removal of phenol from wastewater ${ }^{8}$ and organic volatiles from wastewater ${ }^{9}$, a combination of reverse osmosis and pervaporation may be very useful.

\section{Experimental}

The membrane to be used was prepared by impregnating cellulose acetate solution through a G2 sintered disc. Cellulose acetate was dissolved in acetone and mixed up with water to which potassium bromide had been added. The materials were taken in the proportion 22.2:66.7:10:1.1 respectively. The cellulose acetate solution was impregnated into a previously thoroughly washed and dried sintered $\mathrm{G} 2$ disc under vacuum at $0-0.5{ }^{\circ} \mathrm{C}$. The disc was then immersed in hot water at $75-80^{\circ} \mathrm{C}$. The impregnated membrane was found to have low permeability which was due to the asymmetric nature of the membrane and in that a dense but thin skin covers the porous surface from which evaporation took place during the course of the preparation of the impregnated membrane. However, the membrane prepared in this way is anisotropic and the flow would show a significant change on the reversal of the direction of the applied force and hence to avoid this, all measurements were carried out in the direction of impregnation of the cellulose acetate solution.

\section{Apparatus}

In present investigation, the apparatus used is meant for measurements with sintered disc impregnated cellulose acetate membrane ${ }^{10}$. The apparatus shown in Figure 1 consisted of Pyrex glass tube of length $20 \mathrm{~cm}$ and diameter $3.0 \times 10^{-2} \mathrm{~cm}$ with sintered disc of porosity $\mathrm{G} 2$ in the middle which was impregnated with cellulose acetate. This tube has two standard female B-24 joints at the end, which are closed. The main Pyrex tube has two side tubes having female B-14 joints to which a capillary tube ' $\mathrm{C}$ ' and a pressure head are connected.

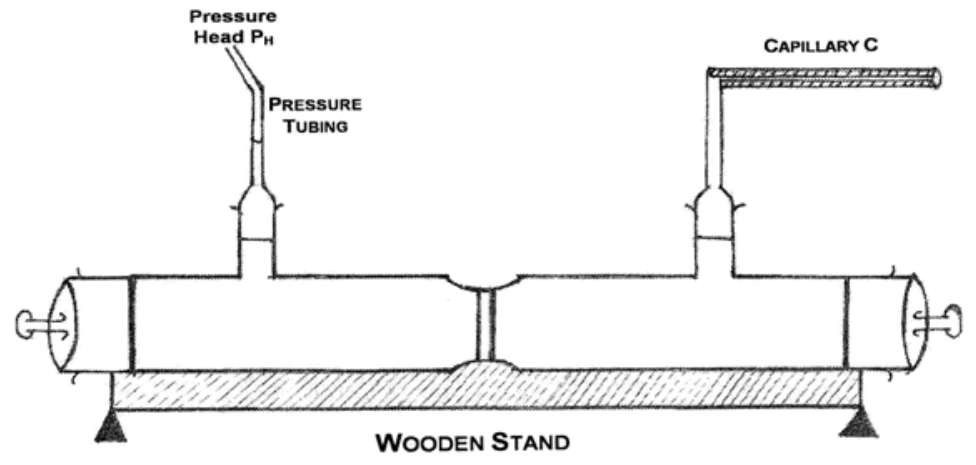

Figure 1. Experimental setup for transport process across anisotropic cellulose acetate membrane

The pressure head is attached to the side tube through a glass tube having a standard male B-14 joint at the lower end. The pressure head is held with the stand and is movable so that pressure can be maintained in the system. The glass apparatus is placed on the wooden stand. 


\section{Determination of $\mathrm{pH}$}

Digital $\mathrm{pH}$ meter was employed for the determination of $\mathrm{pH}$, before the determination of $\mathrm{pH}$ of the sample $\mathrm{pH}$ meter was calibrated by using two different standard buffer solutions of different $\mathrm{pH}$ values.

\section{Determination of conductivity}

Digital conductivity meter was employed for the determination of conductivity, before the determination of conductivity of the sample conductivity meter was calibrated by using $0.1 \mathrm{~N} \mathrm{KCl}$ solution.

\section{Determination of viscosity}

Ostwald's viscometer calibrated with double distilled water was employed for the determination of viscosity. The electronic stop watch was employed to measure the time of flow. The viscosity can be determined by using the formula

$$
\eta_{2}=\eta_{1}\left(t_{2} / t_{1}\right)\left(\rho_{2} / \rho_{1}\right)
$$

Where, $\eta_{1}$ is the viscosity of water, $\rho_{1}$ is the density of water, $t_{1}$ is the time of flow of water, $\eta_{2}$ is the viscosity of water sample, $\rho_{2}$ is the density of water sample, $t_{2}$ is the time of flow of water sample

\section{Anion analysis by ion chromatography}

Anion analysis was carried out by using ion chromatograph of Metrohm with data source conductivity detector 1 (850 Professional IC 1), recording time-28.0 min, column type- Metrosep A Supp 5-250/4.0, Eluent composition-3.2 $\mathrm{mM} \mathrm{Na}_{2} \mathrm{CO}_{3}+1 \mathrm{mM} \mathrm{NaHCO}_{3}$, flow rate- $0.7 \mathrm{~mL} / \mathrm{min}$.

\section{Results and Discussion}

The present investigation comprises the purification of various waste water samples by transporting them across anisotropic cellulose acetate membrane using different analytical parameters. The properties investigated are $\mathrm{pH}$, conductivity, viscosity and anion analysis by ion chromatography. Figure 2-15 represents the anion analysis by ion chromatography of various waste water samples before and after transporting them across anisotropic cellulose acetate membrane. These figures show that there occurs a small decrease in the concentration of different anions present in various waste water samples when they are transported across anisotropic cellulose acetate membrane.

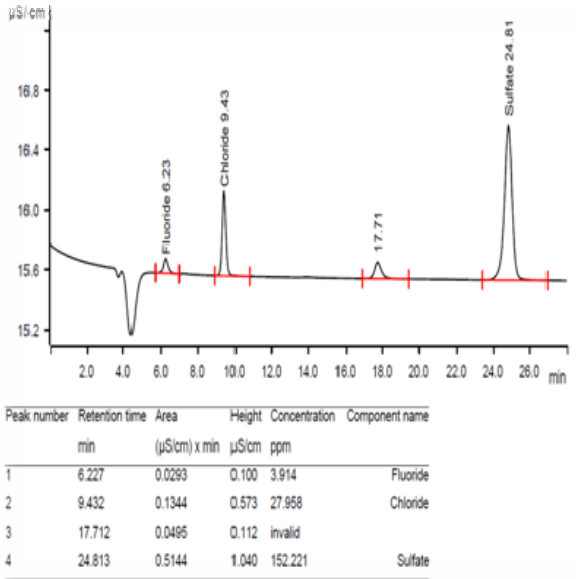

Figure 2. Tap water before transport

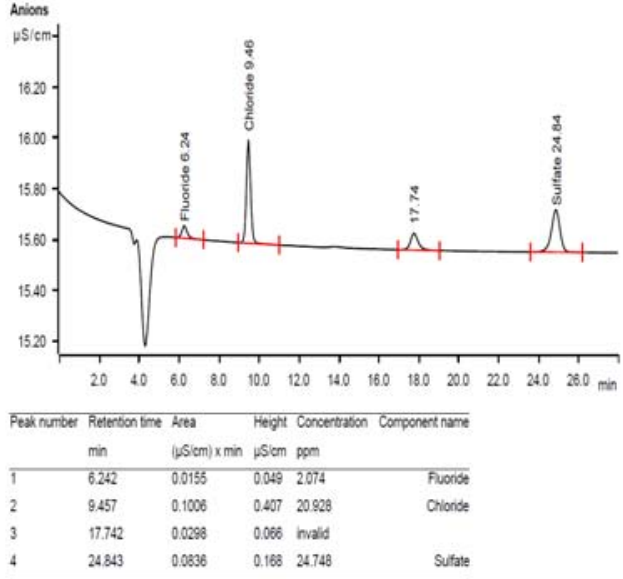

Figure 3. Tap water after transport 


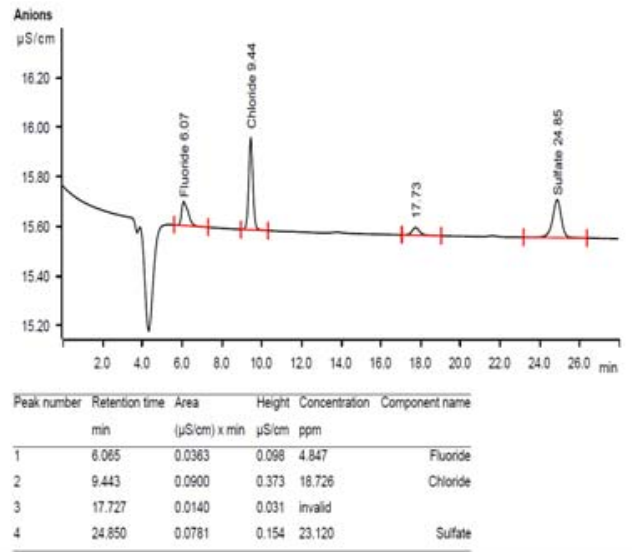

Figure 4. River water before transport

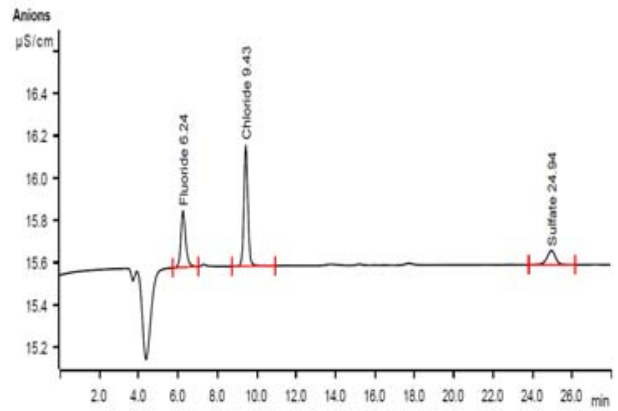

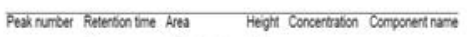

\begin{tabular}{|c|c|c|c|c|}
\hline & $\operatorname{mn}$ & $(\mu \mathrm{S}$ comin) $\times \min$ & ${ }^{\prime}$ Sion ppom & \\
\hline$T$ & 6243 & 0.0743 & $0.288 \quad 18606$ & Fuonse \\
\hline 2 & 9.433 & 0.1333 & $0.571 \quad 49.650$ & Chloride \\
\hline 3 & 24.943 & 0.0334 & $0.088 \quad 16829$ & Suthe \\
\hline
\end{tabular}

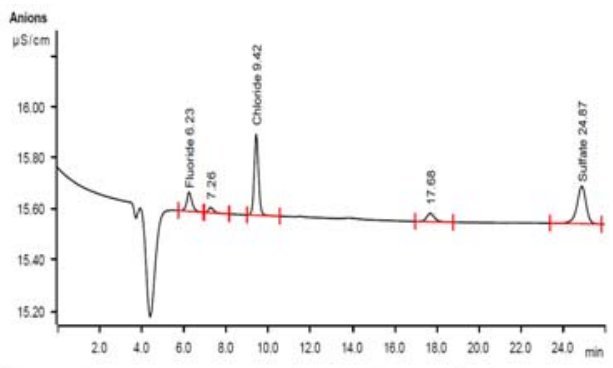

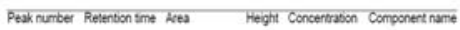

\begin{tabular}{|c|c|c|c|}
\hline $\min$ & (LSSem) $x$ min & LSicm ppm & \\
\hline 8.232 & 0.0216 & $0.075 \quad 2881$ & Fuorde \\
\hline 7.255 & 0.0059 & 0.021 inalid & \\
\hline 9.422 & 0.0749 & $0.319 \quad 15.574$ & Olaride \\
\hline 17.680 & 00144 & 0.033 inalit & \\
\hline 24.873 & 0.0737 & $0.148 \quad 21.825$ & Sultote \\
\hline
\end{tabular}

Figure 5. River water after transport

Anions

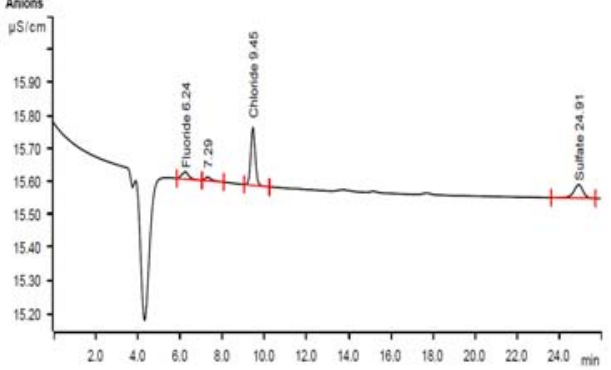

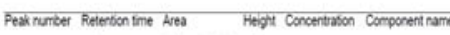

min (uSiemixmin $u S$ iom $\mathrm{men}$

$0.0038 \quad 0.0221167 \quad$ Fivoride

$0.0040 \quad 0.011$ had

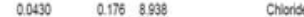

$24.507 \quad 0.0206 \quad 00416091 \quad$ Sultat

Figure 6. Underground water before transport Figure 7. Underground water after transport
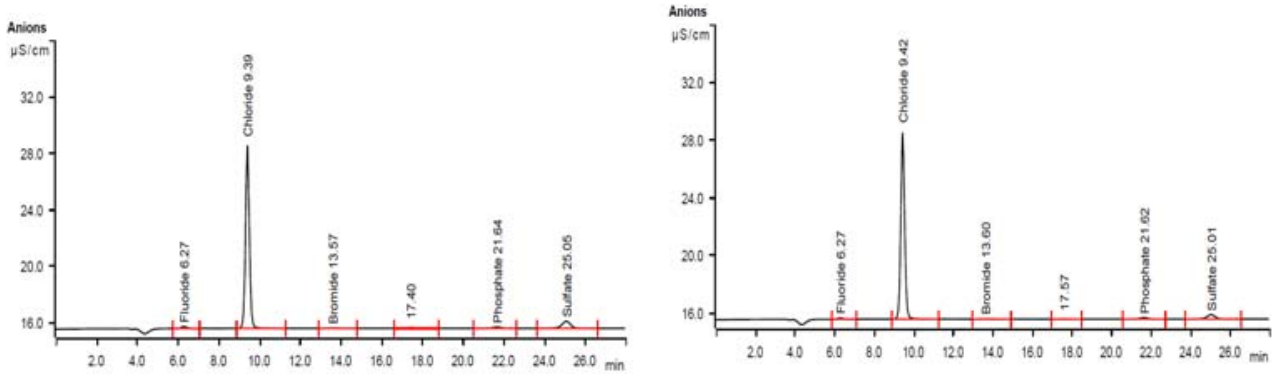

\begin{tabular}{|c|c|c|c|c|c|}
\hline \multirow[t]{2}{*}{ Pezik number } & \multirow{2}{*}{$\begin{array}{l}\text { Reterison bime } \\
\min \end{array}$} & \multirow{2}{*}{$\begin{array}{l}\text { Area } \\
(\text { HSicm) } x \min \end{array}$} & \multirow{2}{*}{$\begin{array}{l}\text { Height } \\
\text { usicen }\end{array}$} & \multirow{2}{*}{$\begin{array}{l}\text { Concertision } \\
\text { ppem }\end{array}$} & \multirow[t]{2}{*}{ Conponert name } \\
\hline & & & & & \\
\hline 1 & 6267 & 0.0459 & 0.155 & 11.545 & Fuoride \\
\hline 2 & 9.396 & 28881 & 12.665 & 9075.463 & Chonde \\
\hline 3 & 13.573 & 00119 & 0.017 & 10.681 & Eromide \\
\hline 4 & 17.396 & 0.0277 & 0005 & invald & \\
\hline 5 & 21.643 & 0.0443 & 0097 & 57.587 & Prosphasen \\
\hline 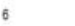 & 25045 & 02521 & 0.510 & 126.875 & sulyse \\
\hline
\end{tabular}

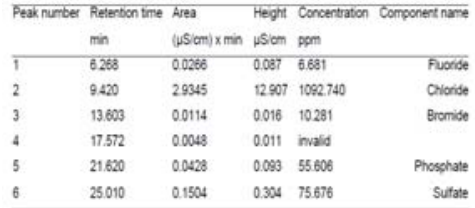

Figure 8. Wastewater from cold drink Figure 9. Wastewater from cold drink industry before transport industry after transport 


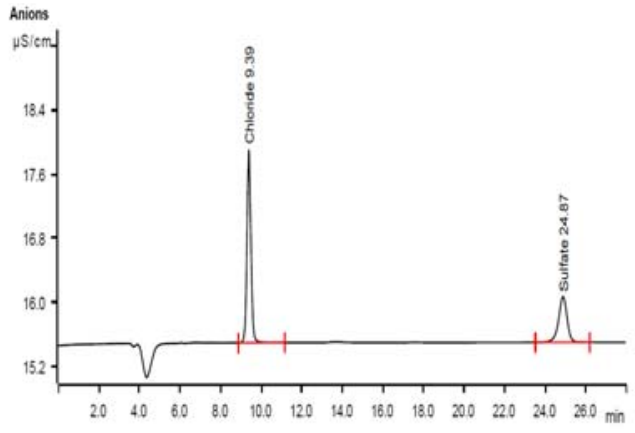

Peaknumber Retention time Avea Height Concentration Component name

\begin{tabular}{|c|c|c|c|c|}
\hline & $\min$ & $(j \mathrm{~S}(\mathrm{~cm}) \times \mathrm{m}$ & $\mu \mathrm{Sem}$ pom & \\
\hline 1 & 9.387 & 0.5438 & $2399 \quad 110572$ & Chlonide \\
\hline 2 & 24.865 & 0.2791 & $0.579 \quad 82530$ & Sultate \\
\hline
\end{tabular}

Figure 10. Detergent wastewater before transport

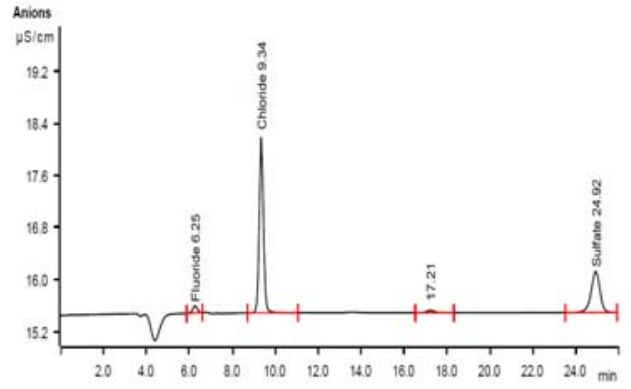

Peaknumber Retertion time Area Heght Concertitation Combonertname

\begin{tabular}{|c|c|c|c|}
\hline $\min$ & (uSlem) $x$ min & $\mu \mathrm{Sicm}$ ppm & \\
\hline 6252 & 0.0282 & $0.111 \quad 3.736$ & Fuonse \\
\hline 9.340 & 0.8042 & $2693 \quad 122841$ & Chlorise \\
\hline 17.212 & 0.0161 & 0.039 invaid & \\
\hline 24.918 & 0.2975 & $0.622 \quad 87.969$ & Suftite \\
\hline
\end{tabular}

Figure 12. Wastewater from Agrochemical industry before transport

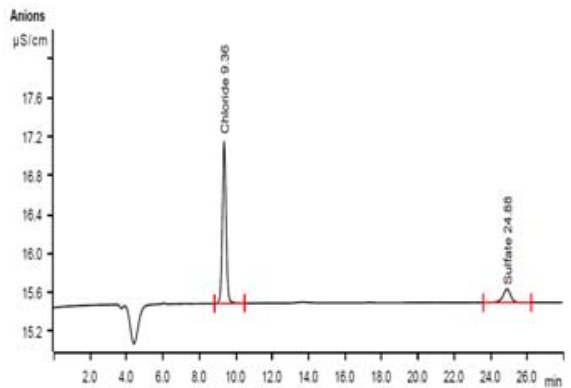

\begin{tabular}{|c|c|c|c|c|}
\hline \multirow[t]{2}{*}{ Peaknumber } & Retertion ime & \multirow{2}{*}{$\begin{array}{l}\text { Avea } \\
(\text { is } \mathrm{sem} \text { ) } \mathrm{xmin}\end{array}$} & \multirow{2}{*}{$\begin{array}{l}\text { Hegtt Concentration } \\
\text { uSem pom }\end{array}$} & \multirow[t]{2}{*}{ Componert name } \\
\hline & $\min$ & & & \\
\hline$T$ & 9.355 & 0.3654 & 108578309 & Crobide \\
\hline 2 & 24.863 & 0,0683 & $0.140 \quad 20.183$ & Sulte \\
\hline
\end{tabular}

Figure 14. Wastewater from paper mill before transport
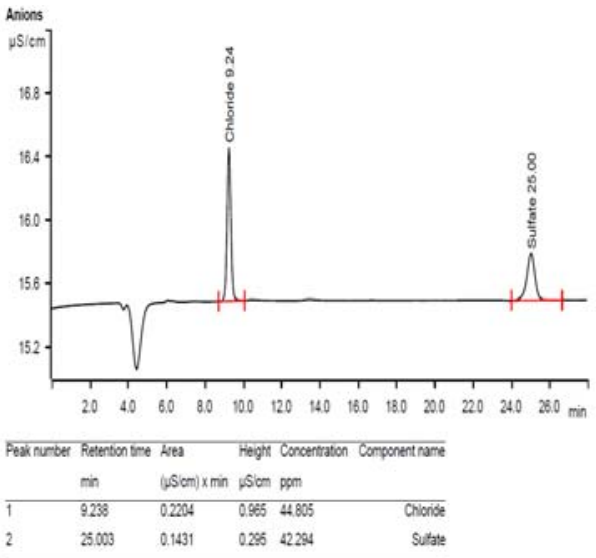

Figure 11. Detergent wastewater after transport
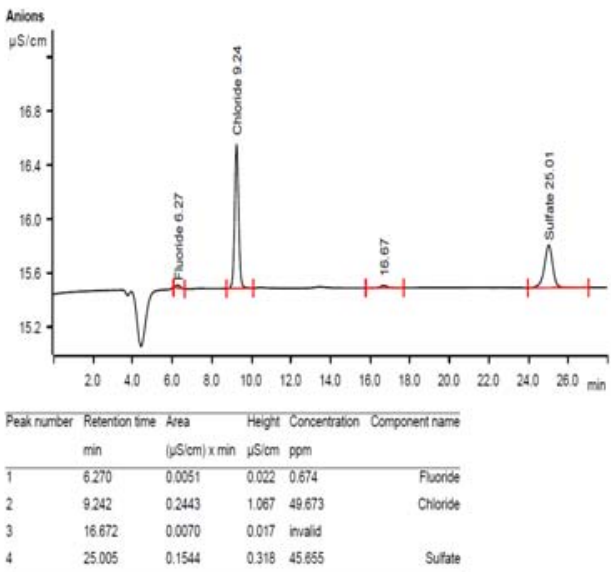

Figure 13. Wastewater from Agrochemical industry after transport
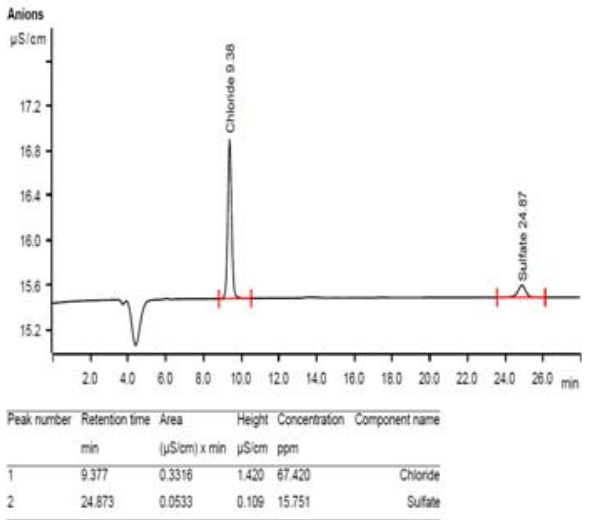

Figure 15. Wastewater from paper mill after transport 
Various parameters such as $\mathrm{pH}$, conductivity, viscosity and anion analysis has been carried out between two types of water samples i.e. water samples directly collected from different water sources as well as from different industries and water samples after transport across anisotropic cellulose acetate membrane. Table 1 shows that there occurs a small increase in the value of $\mathrm{pH}$ when water samples were transported across anisotropic cellulose acetate membrane. This may be attributed to the removal of some acidic species or a decrease in their concentration during transport process. Table 2 shows that there occurs a small decrease in the value of specific conductance when water samples were transported across anisotropic cellulose acetate membrane and this decrease is due to the reason that some ionic species have been removed during transport process as specific conductance decreases with decrease in concentration of ionic species. Table 3 shows that there occurs a small decrease in the value of viscosity when water samples were transported across anisotropic cellulose acetate membrane which is due to small decrease in concentration. A decrease of $1 \times 10^{1}$ to $5 \times 10^{1} \mathrm{kgm}^{-1} \mathrm{~s}^{-1}$ was observed between two types of water samples. Thus this membrane has efficiency to remove dissolved species from aqueous samples especially acidic species indicated by increase in $\mathrm{pH}$ and also ionic species indicated by ion chromatography. A decrease in conductivity also signifies that the concentration of ionic species has been reduced to some extent.

Table 1. $\mathrm{pH}$ values of various samples before and after transport through anisotropic cellulose acetate membrane

\begin{tabular}{clcc}
\hline S. No. & \multicolumn{1}{c}{ Name of the sample } & $\begin{array}{c}\text { Value of } \mathrm{pH} \\
\text { before filtration }\end{array}$ & $\begin{array}{c}\text { Value of } \mathrm{pH} \\
\text { after filtration }\end{array}$ \\
\hline 1. & Tap water & 8.49 & 8.53 \\
2. & River water & 8.37 & 8.53 \\
3. & Under ground water & 8.12 & 8.60 \\
4. & Waste water from paper mill & 7.62 & 7.86 \\
5. & Waste water from cold drink industry & 8.49 & 9.02 \\
6. & Waste water from agrochemical industry & 6.90 & 7.66 \\
7. & Detergent waste water & 7.73 & 7.93 \\
\hline
\end{tabular}

This table shows that there occurs a small increase in the value of $\mathrm{pH}$ when water samples were transported across anisotropic cellulose acetate membrane

Table 2. Conductivity values of various samples before and after transport through anisotropic cellulose acetate membrane

\begin{tabular}{|c|c|c|c|}
\hline S. No. & Name of the sample & $\begin{array}{c}\text { Value of } \\
\text { conductivity } \times 10^{-2} \text { in } \\
\mathrm{mS} \text { before filtration }\end{array}$ & $\begin{array}{c}\text { Value of } \\
\text { conductivity } \times 10^{-2} \text { in } \\
\text { mS after filtration }\end{array}$ \\
\hline 1. & Tap water & 34.81 & 33.84 \\
\hline 2. & River water & 33.84 & 32.88 \\
\hline 3. & Under ground water & 39.65 & 38.68 \\
\hline 4. & Waste water from paper mill & 88.96 & 84.13 \\
\hline 5. & $\begin{array}{l}\text { Waste water from cold drink } \\
\text { industry }\end{array}$ & 259.16 & 257.22 \\
\hline 6. & $\begin{array}{l}\text { Waste water from agrochemical } \\
\text { industry }\end{array}$ & 27.08 & 25.14 \\
\hline 7. & Detergent waste water & 94.77 & 92.83 \\
\hline
\end{tabular}

This table shows that there occurs a small decrease in the value of specific conductance when water samples were transported across anisotropic cellulose acetate membrane 
Table 3. Viscosity of various samples before and after transport through anisotropic cellulose acetate membrane

\begin{tabular}{clcc}
\hline S.No. & \multicolumn{1}{c}{ Name of the sample } & $\begin{array}{c}\text { Viscosity } \\
\text { before filtration } \\
\times 10^{1}\left(\mathrm{kgm}^{-1} \mathrm{~s}^{-1}\right)\end{array}$ & $\begin{array}{c}\text { Viscosity after } \\
\text { filtration } \times 10^{1} \\
\left(\mathrm{kgm}^{-1} \mathrm{~s}^{-1}\right)\end{array}$ \\
\hline 1. & Tap water & 166.39 & 163.90 \\
2. & River water & 170.13 & 167.66 \\
3. & Under ground water & 167.62 & 165.12 \\
4. & Waste water from paper mill & 167.67 & 166.41 \\
5. & Waste water from cold drink industry & 166.54 & 162.77 \\
6. & Waste water from agrochemical industry & 168.89 & 166.38 \\
7. & Detergent waste water & 168.90 & 165.15 \\
\hline
\end{tabular}

This table shows that there occurs a small decrease in the value of viscosity when water samples were transported across anisotropic cellulose acetate membrane

\section{References}

1. Mulder M, Basic Principles of Membrane Technology; Kluwer Academic Publishers: Dordrecht, $2^{\text {nd }} E d ., 1996$.

2. Sinnott R K, Coulson J M and Richardson J F, Chemical Engineering Design; Elsevier Butterworth-Heinemann: Jordan Hill Oxford, $4^{\text {th }}$ Ed., 2005.

3. Rausch K D, Membrane Technology in the Starch Processing Industry, 2002, 54(7), 273-284.

4. Penzhom R D, Fus Tech.., 1988, 14, 450.

5. Violante V, Fus Eng Des., 1993, 22(3), 257-263; DOI:10.1016/0920-3796(93)90120-7

6. Yoshida H, Nucl Tech Fus., 1983, 3, 471.

7. Milby K H, Steinmeyer D E and Tripodi M K, Ion Exchange Hollow Fiber Membranes for Protein Purification, 1990, 1, 625.

8. Rautenbach $\mathrm{R}$ and Klatt S, Treatment of Phenol-Contaminated Wastewater by Reverse Osmosis/Pervaporation in the Water-Treatment Industry; Bakish R, Ed., $1991,392$.

9. Schofield R W, McCray S C and Ray R J, Opportunities for Pervaporation in the Water-Treatment Industry, Bakish R, Ed., 1991, 409.

10. Sharma M, Salathia M, Sharma A, Sharma S and Gupta D, Res J Chem Environ., 2005, 9, 64 . 